\title{
Relations entre cultures, hier et aujourd'hui
}

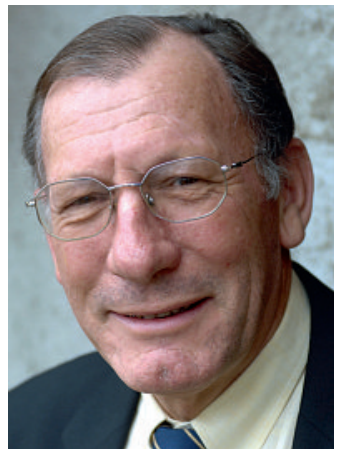

Jean Martin
Le DOCIP [1] est une ONG qui s'engage pour les droits des peuples autochtones, les assistant notamment au sein des Nations Unies. Son bulletin Update de marsmai 2009 fait rapport sur une réunion consacrée à «Changements climatiques, diversité bioculturelle et moyens d'existence: le rôle de gardien des peuples autochtones»; réunion qui a mis en évidence l'expérience de première main des peuples autochtones, leur vulnérabilité aux changements climatiques, ainsi que la nécessité de les impliquer dans les négociations mondiales. Pour ma part, il y a bien quarante ans que je m'intéresse à nos congénères qui ont des cadres de référence socio-culturels différents et saisis l'occasion estivale d'évoquer quelques lectures.

Dans un livre déjà ancien qui garde sa pertinence, d'une personnalité qui a été un porte-parole des Native Americans ou First Nations [2]: «Quand la compétition est libérée de sa fondation économique, comme c'est le cas dans les tribus indiennes, la vie prend un tout autre aspect. Le statut dépend de la manière dont une personne apporte des contributions à sa communauté»; «Le résultat de cet ordre social étrange (des Etats-Unis) est que le monde naturel est totalement négligé. La Terre n'est considérée que comme une matière première de plus (...) L'Indien vivait avec sa terre, craignant de la détruire. Il comprenait qu'il fallait que toute vie se respecte et respecte les autres formes de vie pour qu'une société puisse se maintenir - respectant même les petits animaux, ce dont les autres riaient (...). Pourtant, bientôt, nous pourrions paniquer et nous tourner religieusement vers le plancton marin en le suppliant de produire suffisamment d'oxygène pour nous permettre de respirer». Voir nos craintes - combien justifiées - actuelles à propos de changements climatiques.

Un ouvrage illustrant des sagesses autochtones [3] souligne comment les aborigènes australiens, parmi d'autres, connaissent et sont marqués par l'unicité des choses et comment leur éducation intègre fortement la notion de communauté: "Mon univers s'étend quand je réalise que nous vivons dans un monde unissant corps et esprit et ceci pour chaque forme de vie, dans le monde vivant aussi bien que non-vivant». «Dans des cérémonies tenues précocement dans leur vie, les enfants apprenaient à penser à ce qui est bon pour la tribu en tant que collectif. Se montrer égoïste ne se voyait simplement pas.» Les valeurs sont autres que matérielles: «L'argent ne peut jamais être une récompense par lui-même. Impossible dans la culture hawaïenne de dire Je veux être payé ce que je vaux»».
Les relations entre cultures qui ont été marquées par le conflit et l'oppression donnent lieu aujourd'hui à de nombreux débats. L'ouvrage de J.-C. Ameisen [4] dont j'ai parlé dans cette rubrique [5] à propos d'évolution du vivant les évoque. Il cite l'écrivain nigérian Ben Okri: «Alors que le gouverneur général (anglais) réécrivait le temps (rendant le sien plus long, le nôtre plus bref), alors qu'il rendait invisibles nos accomplissements, effaçait les traces de nos civilisations, réécrivait la signification et la beauté de nos coutumes, alors qu'il transformait notre philosophie en superstitions, nos rituels en danses enfantines, alors qu'il réécrivait notre passé, il altéra notre présent.» Ethnocentrisme... Et, si souvent, la situation du pot de terre contre le pot de fer.

En rapport avec l'esclavage: «Puis des nations vont proclamer à la face du monde leur volonté de libération universelle. Le 4 juillet 1776, les Etats-Unis adoptent leur Déclaration d'indépendance («Nous tenons pour évidentes par elles-mêmes les vérités suivantes: Tous les hommes sont créés égaux>...). L'esclavage sera maintenu. La nuit du 4 août 1789, la Révolution française abolit tous les privilèges féodaux. Mais l'esclavage est maintenu. Puis est adoptée la Déclaration des droits de l'homme et du citoyen. Mais l'esclavage est maintenu.» Ameisen fait référence à ce que Hannah Arendt dira plus tard de l'effrayante «banalité du mal».

Plus loin: «Et là où l'esclavage a été aboli, la fin de l'esclavage ne sera pas la fin du temps du mépris. Ni la fin des massacres, du racisme, de l'exclusion et de la discrimination. Dans la nuit, au cœur de cette violence qui renaît sous des formes nouvelles, il y a toujours la même empreinte. Celle de l'exploitation. De l'indifférence. Du mépris, de la peur archaïque de l'autre. Il y a toujours cette ivresse meurtrière de classer, de hiérarchiser. Et cette rationalisation qui vient légitimer la haine.»

Une formule maori qui nous servirait bien ici et maintenant: «L'inéquité survient quand un groupe est traité selon les termes de la culture d'un autre groupe». Y réfléchir à propos de l'initiative contre les minarets sur laquelle nous allons voter prochainement.

On se respecte mieux (soi-même!) si on respecte les différences.

Dr Jean Martin, membre de la rédaction et de la Commission nationale d'éthique 